\title{
An improved synthesis of ultrafiltration zirconia membranes via the sol-gel route using alkoxide precursor
}

\author{
Jeffrey Chi-Sheng Wu*, Li-Chuen Cheng \\ Department of Chemical Engineering, National Taiwan University, Taipei 10617, Taiwan
}

Received 22 June 1999; received in revised form 23 August 1999; accepted 27 August 1999

\begin{abstract}
Crack-free ultrafiltration zirconia membranes were synthesized using zirconium butoxide via the sol-gel route. Unlike the conventional technique, the esterification of anhydrous butanol and glacial acetic acid provided the hydrolyzing water. In addition, acetic acid also served as a chelating ligand to stabilize the hydrolysis-condensation process and minimize the agglomeration of zirconia. Esterification was verified by its product, butyl acetate, as identified by a GC/Mass. FTIR spectrum confirmed the presence of bidental ligand. $\mathrm{HNO}_{3}$ was used to perform the peptization, creating a stable particulate sol with $\mathrm{pH}$ near 1 . The sol was spin-coated on anodic alumina discs, dried under programmed temperature and humidity, then calcined at $500^{\circ} \mathrm{C}$ to remove organics. Grazing incident XRD verified that the zirconia membrane was partially transformed to the tetragonal phase. SEM showed a uniform layer $0.15 \mu \mathrm{m}$ thick on top of the support. Based on nitrogen permeation, the flow-average pore diameter of the $\mathrm{ZrO}_{2}$ membrane was estimated near $3.6 \mathrm{~nm}$. The pore size distribution of unsupported zirconia was measured from nitrogen adsorption/desorption indicating two modes, centered at 1.5 and $3.6 \mathrm{~nm}$, respectively. TEM revealed that the particle size of zirconia ranged from 5 to $10 \mathrm{~nm}$. Our results illustrate that $\mathrm{ZrO}_{2}$ layer is the closed-packing of nano-size spherical particles. Supported zirconia membrane was tested by a cross-flow ultrafiltration. The rejection of soybean oil/hexane solution achieved 37\% which was much better than that of bare disc. (C2000 Elsevier Science B.V. All rights reserved.
\end{abstract}

Keywords: Zirconia; Porous membrane; Sol-gel; Gas permeation; Ultrafiltration

\section{Introduction}

Ceramic membranes are highly promising for use in current separation technology, particularly at high temperatures and in chemically harsh conditions. Ceramic membranes not only have excellent thermal and mechanical properties, but are also resistant to organic solvent and microbiological attack. The unique prop-

\footnotetext{
* Corresponding author. Tel.: +886-2-23631994; fax: +886-2-23623040.

E-mail address: cswu@ccms.ntu.edu.tw (J.C.-S. Wu).
}

erties of ceramics make them appropriate for many more applications in chemical plants than their organic polymer counterparts. An important application is membrane reactors, capable of enhancing conversion and selectivity by removing product(s) during reactions simultaneously [1]. Zirconia, a widely used ceramic membrane, can be used in aqueous filtration with much better alkali durability than other ceramic membranes, such as alumina and silica [2]. In addition, zirconia membrane allows steam sterilization and cleaning with caustic solution [3]. Porous zirconia membrane is stacked with spherical particles resulting 
in higher liquid permeation flux. Studies showed that the drinking water flux of $\mathrm{ZrO}_{2}$ membrane was 5-10 times higher than that of $\mathrm{Al}_{2} \mathrm{O}_{3}$ under the same pore size [4].

Sol-gel technique does not require complicated instruments like chemical vapor deposition in membrane preparation. It provides a simple and easy means of synthesizing nano-size particles, which is essential for ultrafiltration membrane. Because of this simplicity, the synthesis of ceramic membranes via sol-gel has received considerable attention [4-7]. Their studies have indicated that stable $\mathrm{ZrO}_{2}$ colloid could be obtained at a low $\mathrm{pH}$ after hydrolyzing zirconium alkoxide. The hydrolysis of mixed metal alkoxides could be controlled through the esterification of acetic acid and alcohols [8-10]. A porous $\mathrm{ZrO}_{2}$ membrane prepared from zirconyl oxalate had a pore diameter near $4 \mathrm{~nm}$ with thickness ranging from 0.1 to $0.3 \mu \mathrm{m}$ [11].

The stability of particulate sol, and its drying and calcination procedures are crucial in obtaining crack-free membranes. The pore size of a porous membrane is determined by the particle size because the pore is the space of particle packing. One of the difficulties in the sol-gel method is that the hydrolysis of zirconium alkoxide is highly sensitive to water. Even if the solution of zirconium alkoxide is stirred vigorously, the rate of hydrolysis is so quick that large agglomerated zirconia particles will be precipitated once water is added. This problem makes the production of an industrial batch impossible. This study presents an improved method of preparing $\mathrm{ZrO}_{2}$ sol by controlling the hydrolysis of zirconium alkoxide through the slowly-released esterification water. In addition, the acetic acid also serves as a chelating ligand to reduce the rate of hydrolysis so that very fine particles can be obtained $[12,13]$. This concept can also be applied to industrial scale sol-gel processes to prepare crack-free supported zirconia membranes. Such membranes have the feature of a thin active membrane with good mechanical support.

\section{Experimental}

The hydrolysis processes were performed in a glove box maintained at a relative humidity near $25 \%$ by purging with tank nitrogen. Zirconium(IV) butoxide $\left(\mathrm{Zr}\left(\mathrm{OC}_{4} \mathrm{H}_{9}\right)_{4}, 76-80\right.$ wt.\% in $n$-butanol, Strem Chem-

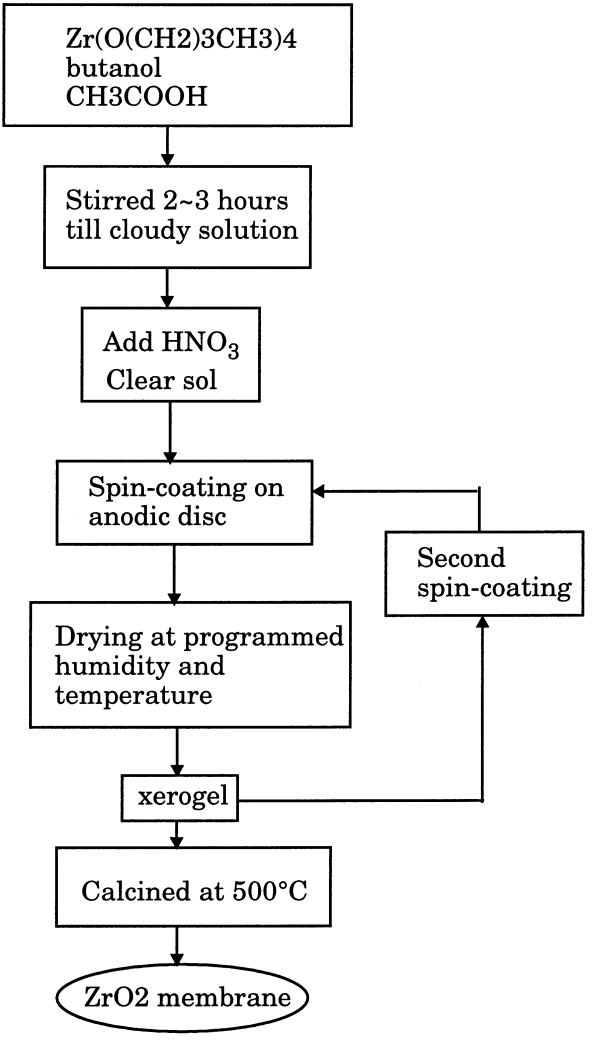

Fig. 1. The sol-gel procedure of $\mathrm{ZrO}_{2}$ membrane synthesis.

icals) was the starting material. To avoid fast precipitation during polycondensation or the formation of unstable colloidal sols, the hydrolyzing water was homogeneously released by the esterification of butanol and acetic acid. Fig. 1 illustrates the procedure of membrane synthesis. Basically, the intention was to provide the stoichiometric amount of water to hydroloyze zirconium butoxide in the hydrolysis process. A typical batch contained $0.01 \mathrm{~mol}$ zirconium butoxide, $0.04 \mathrm{~mol}$ anhydrous butanol (min. 99.8\%) and 0.04 mol glacial acetic acid (min. 99.7\%). The clear solution was stirred for 2-3 h then became cloudy, indicating the zirconium butoxide was hydrolyzed. The $\mathrm{pH}$ value of the solution was measured to be near 5. To rule out the influence of moisture in the glove box during hydrolysis, a test was performed without adding glacier acetic acid into the zirconia butoxide/butanol mixture. In this test the mixture remained clear even after $24 \mathrm{~h}$ of stirring, indicating negligible hydrolysis. The analysis of hydrolyzed sol by a GC/Mass 
(HP GCD plus) identified the product of esterification, butyl acetate. Hydrolyzed zirconia solution was then peptized by $0.5 \mathrm{ml} \mathrm{HNO}_{3}(70 \%)$. The sol became transparent again and the $\mathrm{pH}$ value was near 1 . The $\mathrm{HNO}_{3}$ peptized sol formed a clear stable particulate sol that remained stable at least for 1 month.

Synrex (Taiwan) spinner was used for spin-coating zirconia particulate sol on a Whatman asymmetrical anodic disc with $4.7 \mathrm{~cm}$ OD. The alumina disc comprises of $0.02 \mu \mathrm{m}$ pores on the top and a bottom structure of $0.2 \mu \mathrm{m}$ straight pores. The total thickness of the disc is near $60 \mu \mathrm{m}$. The disc was initially spun-up to $1500 \mathrm{rpm}$. Approximately $2 \mathrm{ml}$ of zirconia sol was dropped in the center of the disc and spun off for $20 \mathrm{~s}$. The spinning speed was then increased to $2000 \mathrm{rpm}$ and another $2 \mathrm{ml}$ of sol was dropped and spun off for additional $25 \mathrm{~s}$. A second spin-coating could be applied after drying, and higher spinning speeds of 2000 and $3000 \mathrm{rpm}$ were used (Fig. 1). The thickness of the coating was only influenced by the characteristics of the solution, the spinning speed and its duration [14]. The amount of zirconia sol was not critical since oversupply was simply spun off. The membrane was dried in a programmable temperature and humidity chamber (Yih-Der Company, Taiwan). The temperature was raised from $30^{\circ} \mathrm{C}$ to $70^{\circ} \mathrm{C}$, increasing at a rate of $10^{\circ} \mathrm{C} / \mathrm{h}$, and the relative humidity was reduced from $80 \%$ to $40 \%$, decreasing at a rate $10 \% / \mathrm{h}$, simultaneously. The temperature and the relative humidity were then maintained at final condition for $30 \mathrm{~min}$. The dried membrane was calcined under air circulation at $500^{\circ} \mathrm{C}$ for $60 \mathrm{~min}$, with an increase of $0.5^{\circ} \mathrm{C} / \mathrm{min}$ from ambient to $200^{\circ} \mathrm{C}$, and then $1.5^{\circ} \mathrm{C} / \mathrm{min}$ to $500^{\circ} \mathrm{C}$. Finally the furnace was turned off and allowed to cool to ambient temperature.

Grazing incident X-ray diffractometer (GIXRD) identified the phase of supported $\mathrm{ZrO}_{2}$ membrane. Incidental X-ray with grazing angle $\left(\sim 3^{\circ}\right)$ was applied to measure the thin layer of $\mathrm{ZrO}_{2}$ on the disc. The morphology and structure were examined by scanning electron microscopy (SEM). SEM samples were sputtered with Pt-carbon film on the supported $\mathrm{ZrO}_{2}$ membrane surface to increase the electrical conductivity. A batch of un-supported zirconia flakes was prepared using the same procedures as the membrane. $\mathrm{ZrO}_{2}$ particles were observed using transmission electron microscopy (TEM). TEM samples were prepared by suspending un-supported zirconia in solvent then dropping solution on a copper-mesh holder. Sample was allowed to dry before TEM analysis. A batch of $\mathrm{ZrO}_{2}$ xerogel was obtained from particulate sol by drying under the same conditions as those of the $\mathrm{ZrO}_{2}$ membrane. Fourier transform infrared spectroscopy (FTIR) was used to identify the chelating ligand. Samples were prepared by pressing pellets of $\mathrm{ZrO}_{2}$ xerogel mixed with $\mathrm{KBr}$. Thermogravimetric analysis (TGA) and differential thermal analysis (DTA) were performed on $\mathrm{ZrO}_{2}$ xerogel to study the weight loss and thermal reactions during calcination. The pore size distribution of un-supported zirconia was calculated from the $\mathrm{N}_{2}$ adsorption/desorption isotherms at $77 \mathrm{~K}$.

The nitrogen permeation of supported $\mathrm{ZrO}_{2}$ membrane was carried out in a disc module at room temperature. The feed-side pressures varied between 101 and $202 \mathrm{kPa}$, and the permeate side was open to the atmosphere. Gas permeate flow ranged from $350-7000 \mathrm{ml} / \mathrm{min}$, depending on membranes. The liquid-phase separation performance of $\mathrm{ZrO}_{2}$ membrane was evaluated by the cross-flow ultrafiltration of soybean oil/hexane solution. The solution, as obtained from Jia-Shin Oil and Grease Company (Taiwan), was directly collected from the solvent extractor in the plant without refining. Detailed procedures of cross-flow ultrafiltration can be found elsewhere [15].

\section{Results and discussion}

\subsection{Hydrolysis and chelation}

Zirconium alkoxide is hydrolyzed and condensed to form polymeric species composed of $\mathrm{M}-\mathrm{O}-\mathrm{M}$ bonds in butanol solution. The process is generally described in Eqs. (1)-(3), where R represents $\mathrm{C}_{4} \mathrm{H}_{9}$.

$\mathrm{Zr}(\mathrm{OR})_{4}+\mathrm{H}_{2} \mathrm{O} \rightarrow \mathrm{Zr}(\mathrm{OR})_{3}(\mathrm{OH})+\mathrm{ROH}$

$\mathrm{Zr}(\mathrm{OR})_{3}(\mathrm{OH})+\mathrm{Zr}(\mathrm{OR})_{3}(\mathrm{OH})$

$\rightarrow(\mathrm{RO})_{3} \mathrm{Zr}-\mathrm{O}-\mathrm{Zr}(\mathrm{OR})_{3}+\mathrm{H}_{2} \mathrm{O}$

$$
\begin{aligned}
& \mathrm{Zr}(\mathrm{OR})_{3}(\mathrm{OH})+\mathrm{Zr}(\mathrm{OR})_{4} \\
& \quad \rightarrow(\mathrm{RO})_{3} \mathrm{Zr}-\mathrm{O}-\mathrm{Zr}(\mathrm{OR})_{3}+\mathrm{ROH}
\end{aligned}
$$




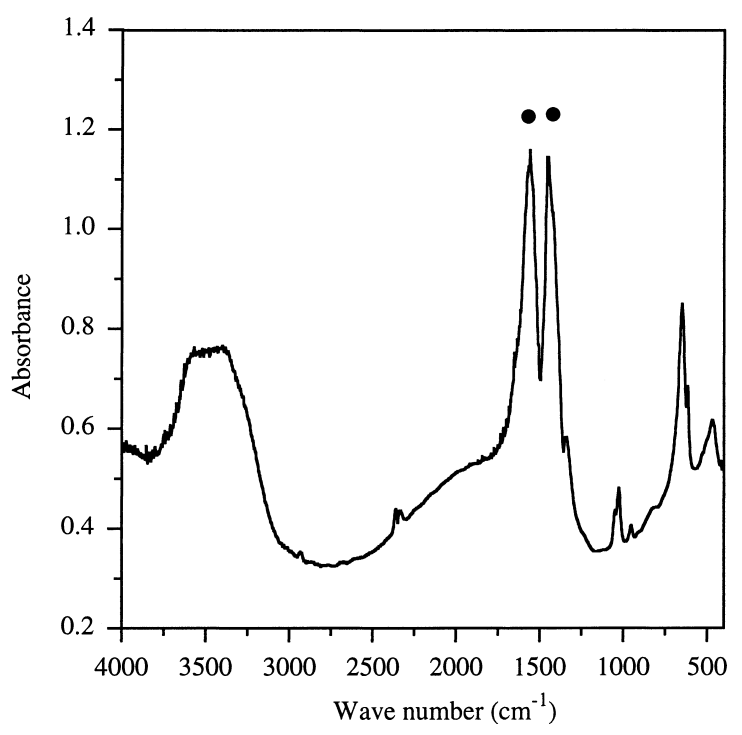

Fig. 2. FTIR spectrum of $\mathrm{ZrO}_{2}$ xerogel.

Hydrolyzing water can be supplied via two different mechanisms. The first mechanism is the esterification of butanol and acetic in situ, as shown Eq. (4). The second one is the oxolation, as shown in Eq. (2). The esterification product, butyl acetate was found and identified by a GC/Mass. The esterification becomes much more favorable when the ratio of acetic acid/metal alkoxide is low [10]. Thus, hydrolysis rate is primarily controlled by esterification of water excluding the air moisture. Acetic acid also serves as a chelating ligand and can change the alkoxide precursor at the molecular level, thus modifying the hydrolysis process [12]. Fig. 2 presents the FTIR spectrum of zirconia xerogel. The adsorption peaks at 1453 and $1561 \mathrm{~cm}^{-1}$ clearly indicate the bidental ligand $\mathrm{CH}_{3} \mathrm{COO}^{-}$. They are very different from acetic acid. Chelation can be described in Eq. (5) [13]. A fast temperature increase $\sim 10^{\circ} \mathrm{C}$ in $10 \mathrm{~s}$ ) also occurred when acetic acid was added to $\mathrm{Zr}$ butoxide/butanol mixture during our experiment. Such a phenomenon is due to the replacement of $\mathrm{O}-n \mathrm{C}_{4} \mathrm{H}_{9}^{-}$with $\mathrm{CH}_{3} \mathrm{COO}^{-}$. The hydrolysis of chelated zirconium complex is deferred so that bidental ligand may still remain in the xerogel. Upon further hydrolysis, bidental ligand is broken off and gives to $\mathrm{Zr}-\mathrm{OH}$ bond. This mechanism decreases the rate of hydrolysis, meaning very fine particles of zirconium hydroxide will be formed and suspended in solution. The fine particulate sol is very stable after $\mathrm{HNO}_{3}$

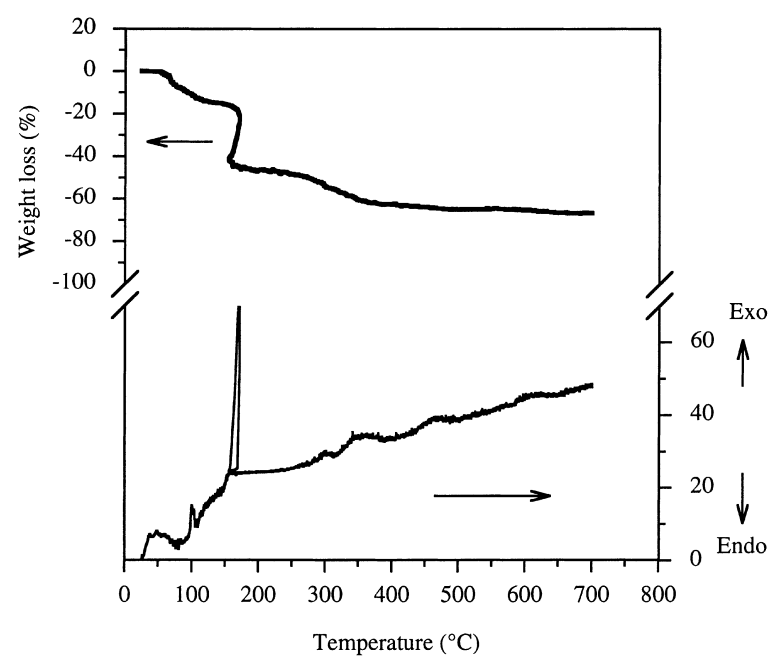

Fig. 3. TGA and DTA of $\mathrm{ZrO}_{2}$ xerogel

peptization, due to the electrostatic repulsion between highly charged particles under low $\mathrm{pH}$ condition [16].

$\mathrm{ROH}+\mathrm{CH}_{3} \mathrm{COOH} \rightarrow \mathrm{H}_{2} \mathrm{O}+\mathrm{RCOOC}_{2} \mathrm{H}_{5}$<smiles>[R]O[Z6]([R20])([R20])C([R20])([R20])O[R]</smiles>

Fig. 3 displays the TGA/DTA results of zirconia xerogel. The weight loss before $120^{\circ} \mathrm{C}$ indicates the vaporization of physically adsorbed water and butanol (b.p. $117.7^{\circ} \mathrm{C}$ ). As the temperature rises, a significant exothermic peak accompanied with weight loss is observed near $160^{\circ} \mathrm{C}$. Possibly, the oxidation of nitro-compounds is the cause of this huge exothermic reaction. The nitro-compounds may be formed by nitration of butyl acetate and $\mathrm{HNO}_{3}$. Exothermic peaks between $360^{\circ} \mathrm{C}$ and $500^{\circ} \mathrm{C}$ imply the combustion of organics, something further suggested by the gradual decrease in weight over the same temperature range. The weight decrease stops above $500^{\circ} \mathrm{C}$ indicating that the loss of organics is completed, as reported by Muñoz-Aguado et al. [9]. Thus, the calcined temperature of $\mathrm{ZrO}_{2}$ membrane is determined to be $500^{\circ} \mathrm{C}$. 


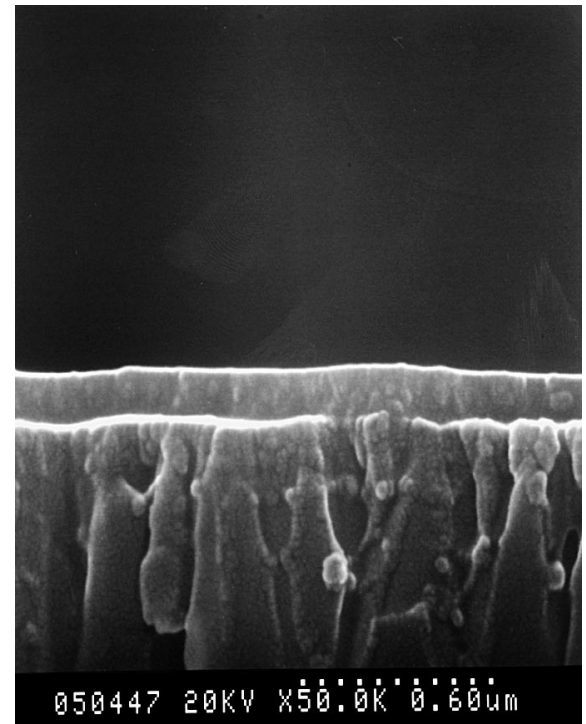

Fig. 4. SEM cross-section of double-coated supported $\mathrm{ZrO}_{2}$ membrane.

\subsection{Characteristics of zirconia membrane}

Fig. 4 shows the SEM cross-section of a $\mathrm{ZrO}_{2}$ membrane prepared with double coatings of $\mathrm{ZrO}_{2}$ sol. A uniform zirconia layer appears on top of the disc. The thickness of the $\mathrm{ZrO}_{2}$ layer is approximately $0.15 \mu \mathrm{m}$. The $\mathrm{ZrO}_{2}$ particles are too small to be distinguished under 50000 magnification by SEM. Other SEM micrographs of single-coated $\mathrm{ZrO}_{2}$ membrane show that no separate top layer can be observed. This implies that most $\mathrm{ZrO}_{2}$ sol was trapped in the $0.02 \mu \mathrm{m}$ pores of disc during the first coating, and might reduce the pore size. Therefore, the $\mathrm{ZrO}_{2}$ sol could stand on the top of disc during the second coating. Fig. 5 displays the TEM micrograph of unsupported $\mathrm{ZrO}_{2}$. Most of the $\mathrm{ZrO}_{2}$ particles are spherical and their diameter is in the range of 5-10 $\mathrm{nm}$. The particles of $\mathrm{ZrO}_{2}$ membrane should be similar to the unsupported $\mathrm{ZrO}_{2}$ since they are prepared by the same procedures. Fig. 6 presents the GIXRD spectrum of the $\mathrm{ZrO}_{2}$ membrane with a broad base line. Peak positions and relative intensities indicate the tetragonal phase of $\mathrm{ZrO}_{2}[11,17]$. The broad base line of spectrum implies the existence of amorphous zirconia, which is a common result in the sol-gel process. In sum, the $\mathrm{ZrO}_{2}$ membrane is a packing of both amorphous and nano-crystal zirconia.

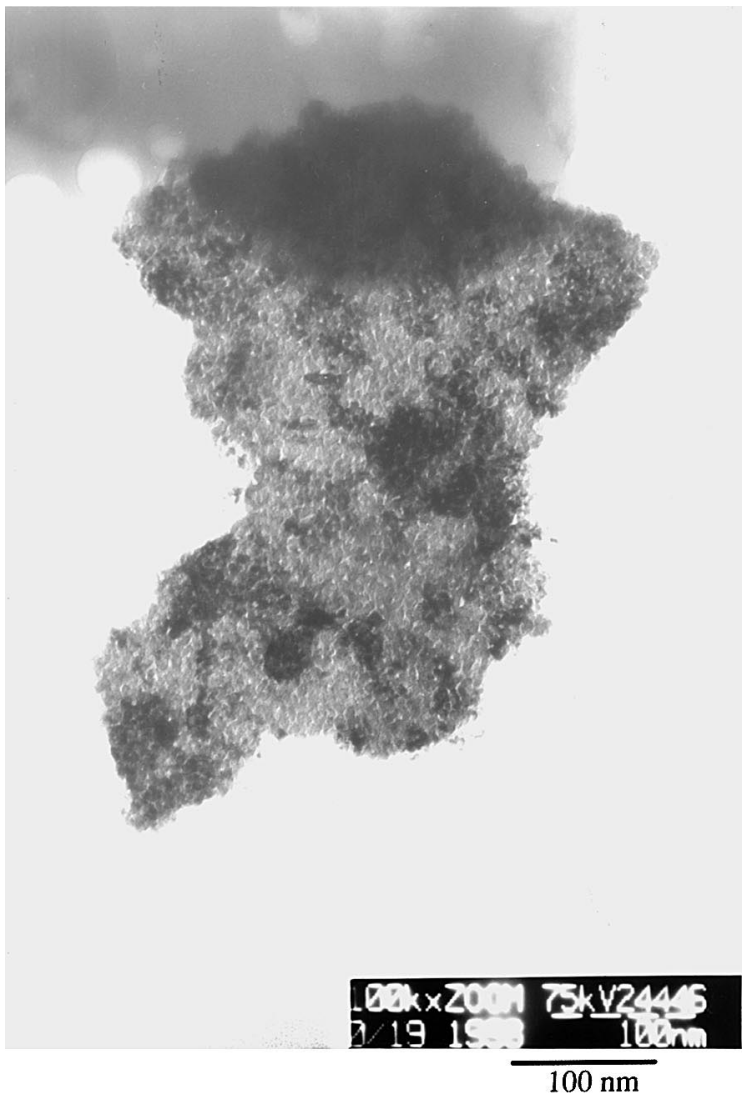

Fig. 5. TEM micrograph of unsupported $\mathrm{ZrO}_{2}$.

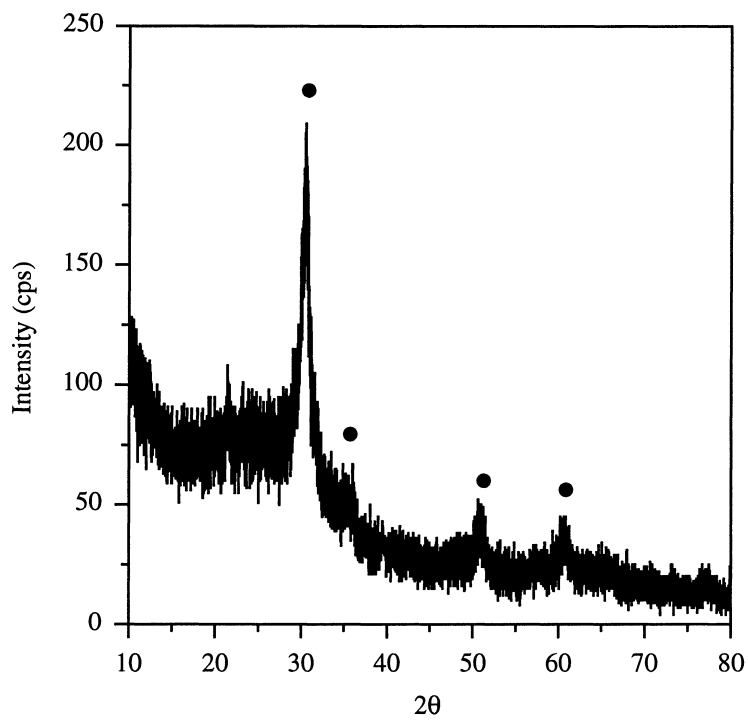

Fig. 6. Grazing angle $\left(3^{\circ}\right) \mathrm{XRD}$ of double-coated $\mathrm{ZrO}_{2}$ membrane. 


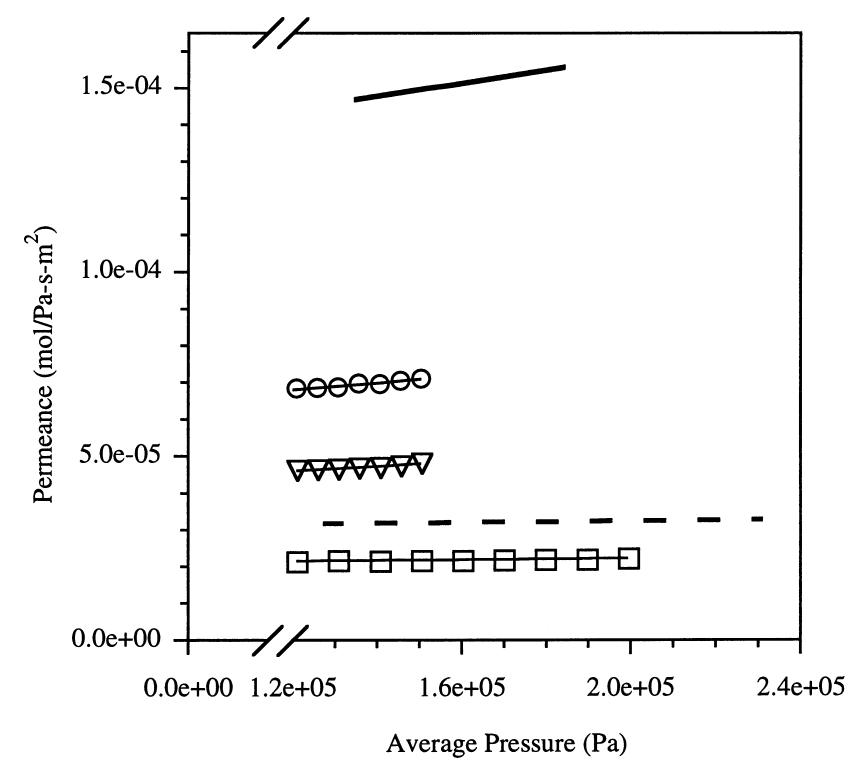

Fig. 7. Nitrogen permeation of calcined membranes, $\bigcirc 0.02 \mu \mathrm{m}$ disc, $\nabla$ single-coated $\mathrm{ZrO}_{2}$ membrane with disc, $\square$ double-coated $\mathrm{ZrO} 2$ membrane with disc, - calculated single-coated $\mathrm{ZrO}_{2}$ layer, - - - calculated double-coated $\mathrm{ZrO}_{2}$ layer.

\subsection{Pore size and pore size distribution}

Fig. 7 depicts the permeation of nitrogen versus various mean transmembrane pressures. In general, porous membrane comprises of two kinds of pores. One is continuous-network pore which can let fluid pass through the membrane. These pores determine the separation performance and permeation flux of a membrane. The other kind are dead-end pores which can be considered as the void of membrane structure and make no contribution to permeation. The gas permeation is primarily contributed by Knudsen and Poiseuille flows in a porous membrane under our permeation condition. The average radius of continuous-network pores can be estimated from the gas permeation data in Eqs (6) and (7) $[18,19]$. The total resistance of gas permeation is the linear combination of resistance of support and membrane for a supported-membrane. Thus, the permeation of a single $\mathrm{ZrO}_{2}$ layer (also shown in Fig. 7) can be calculated based on the resistance-in-series model [20]. The flow-average pore diameters of the disc and a single $\mathrm{ZrO}_{2}$ layer can be calculated from their slopes $(\beta)$ and intercepts $(\alpha)$, which are obtained by linear regression from Fig. 7. Table 1 lists the calculated Knudsen permeances and flow-average pore diameters of disc
Table 1

Calculated $\mathrm{N}_{2}$ permeances and estimated pore diameters of membranes

\begin{tabular}{|c|c|c|}
\hline & $\begin{array}{l}\text { Knudsen permeance } \\
\left(\mathrm{mole} /\left(\mathrm{m}^{2} \mathrm{~Pa} \mathrm{~s}\right)\right)\end{array}$ & $\begin{array}{l}\text { Pore } \\
\text { diameter }(\mathrm{nm})\end{array}$ \\
\hline $0.02 \mu \mathrm{m}$ disc & $5.67 \times 10^{-5}$ & 17.6 \\
\hline $\mathrm{ZrO}_{2}$ membrane $^{\mathrm{a}}$ & $1.23 \times 10^{-4}$ & 15.5 \\
\hline $\mathrm{ZrO}_{2}$ membrane ${ }^{\mathrm{b}}$ & $3.04 \times 10^{-5}$ & 3.6 \\
\hline
\end{tabular}

\footnotetext{
${ }^{\text {a }}$ Single coated.

${ }^{\mathrm{b}}$ Double coated.
}

and sole $\mathrm{ZrO}_{2}$ membranes, respectively. Knudsen permeance is determined by extrapolating permeance to zero pressure, that excludes the Poiseuille flows. The flow-average pore diameter of the disc is $\sim 18 \mathrm{~nm}$. This value is close to the $0.02 \mu \mathrm{m}$ pore disc supplied by manufacturer. The average pore diameters are reduced to 15 and $3.6 \mathrm{~nm}$ for single and double coating membranes, respectively. The former pore is reduced by the entrapped $\mathrm{ZrO}_{2}$ particles within pores, while the latter is the pores of the top $\mathrm{ZrO}_{2}$ layer (Fig. 4).

$$
\begin{aligned}
& \frac{F}{L}=\alpha+\beta p_{\text {avg }} \\
& r=\left[3.162 \mu\left(\frac{R T}{M}\right)\right]\left(\frac{\beta}{\alpha}\right)
\end{aligned}
$$




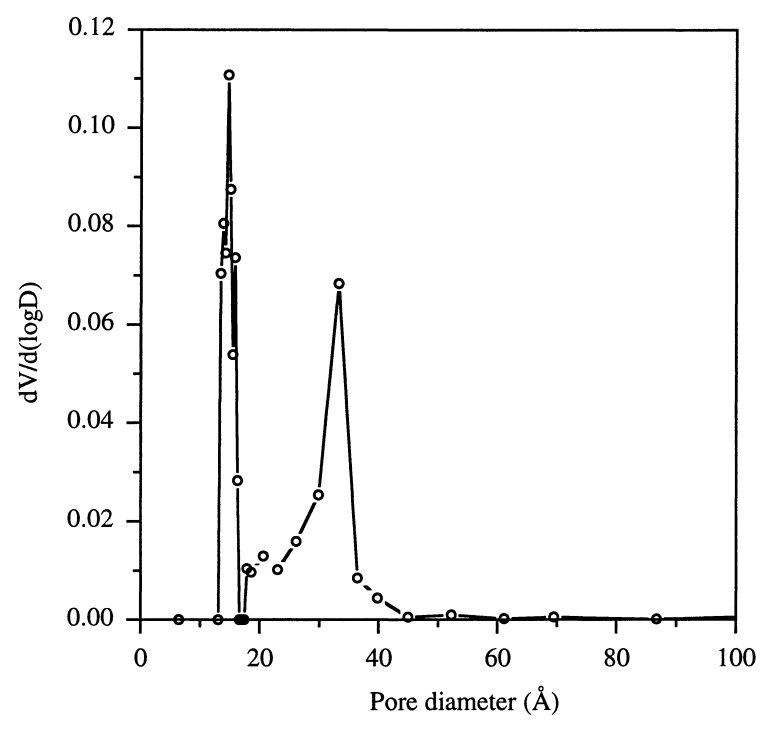

Fig. 8. Pore size distribution of unsupported $\mathrm{ZrO}_{2}$ by nitrogen adsorption/desorption.

Fig. 8 displays the pore size distribution of unsupported zirconia calculated from nitrogen desorption isotherm. Pore size distribution is split into two modes, and the average pore diameters are at $\sim 1.5$ and $\sim 3.6 \mathrm{~nm}$, respectively. Total porosity is approximately $10 \%$ estimated from the nitrogen adsorption volume. Such low porosity could be due to the sintering of very fine $\mathrm{ZrO}_{2}$ particles. The specific surface area is approximately $4 \mathrm{~m}^{2} / \mathrm{g}$ calculated by BET equation. The drying of stable sol can give denser material because particle repulsion avoids aggregation, and the particles move around until the most compact packing is formed [5]. Because of this behavior, calcined $\mathrm{ZrO}_{2}$ membrane could form a closed-packed solid sphere. The pore volume is created from the space of $\mathrm{ZrO}_{2}$ particle packing. From above results, the dead-end pores may possess an average diameter of approximately $1.5 \mathrm{~nm}$, and contribute to the microporosity of the membrane. The continuous-network pores may contribute to the mesoporosity, which has an average diameter near $3.6 \mathrm{~nm}$. This diameter is consistent with the flow-average diameter from gas permeation (Table 1). If we assume that the mesoporosity contributes the continuous-network pores, the tortuosity $(\tau)$ of the $\mathrm{ZrO}_{2}$ layer can be estimated by using Eq. (8). Tortuosity can only be calculated if mesoporosity and permeate rates are known. The
Table 2

Cross-flow ultrafiltration of soybean oil/hexane solution ${ }^{\mathrm{a}}$

\begin{tabular}{llll}
\hline Soybean oil/hexane solution & Support $^{\mathrm{b}}$ & $\mathrm{ZrO}_{2}{ }^{\mathrm{c}}$ & $\mathrm{ZrO}_{2}{ }^{\mathrm{d}}$ \\
\hline Feed (wt.\%) & 34.7 & 30.3 & 31.3 \\
Permeate (wt\%) & 28.7 & 23.8 & 19.6 \\
Rejection (\%) & 17 & 21 & 37 \\
Stage cut & 0.033 & 0.0052 & 0.009
\end{tabular}

${ }^{a}$ Cross-flow filtration condition: transmembrane pressure 505-606 kPa, paddle agitation $120 \mathrm{rpm}$, Soybean oil concentration measured by UV adsorption at $458 \mathrm{~nm}$.

${ }^{\mathrm{b}} 0.02 \mu \mathrm{m}$ anodic disc, $\mathrm{Wu}$ and Lee [15].

${ }^{\mathrm{c}}$ Single-coated supported $\mathrm{ZrO}_{2}$ membrane.

${ }^{\mathrm{d}}$ Double-coated supported $\mathrm{ZrO}_{2}$ membrane.

${ }^{\mathrm{e}}$ Rejection $=$ (oil conc. of feed - oil conc. of perm $) /($ oil conc. of feed) $\times 100 \%$.

mesoporosity of membrane is estimated to be near $4 \%$ (Fig. 8). The Knudsen permeance of top $\mathrm{ZrO}_{2}$ layer is $3.04 \times 10^{-5} \mathrm{~mol} /\left(\mathrm{m}^{2} \mathrm{Pas}\right.$ ) (Table 1$)$. The thickness of the $\mathrm{ZrO}_{2}$ layer is near $0.15 \mu \mathrm{m}$ (Fig. 4). Thus, the tortuosity is estimated to be $\sim 1.9$. This value is lower than that of traditional alumina membrane, which is normally $\sim 3.9$. This supplementary evidence indicates that the zirconia layer is constructed of spherical particles while the particles in the alumina layer are plate-shaped [6].

$$
\left(\frac{F}{L}\right)_{0}=\alpha=31.62\left(\frac{1}{L}\right)\left(\frac{\varepsilon}{\tau}\right) r \sqrt{\frac{1}{R T M}}
$$

\subsection{Cross-flow ultrafiltration}

A cross-flow ultrafiltration of soybean oil/hexane solution was used to evaluate the separation performance of supported $\mathrm{ZrO}_{2}$ membrane. Specifically, this work was done to show the defect free nature of the $\mathrm{ZrO}_{2}$ membrane studied here. Table 2 summarizes the separation results. The molecular weight of soybean oil is estimated to be approximately $900 \mathrm{~g} / \mathrm{mole}$. A previous separation study reported that $17 \%$ rejection could be achieved using a bare $0.02 \mu \mathrm{m}$ disc [15]. Under the same filtration conditions of previous study, the rejection increases to $21 \%$ and $31 \%$ on single and double coating $\mathrm{ZrO}_{2}$ membranes, respectively. The separation performance improves significantly because the pore size is reduced. Compared with bare disc, the stage cut reduction of $\mathrm{ZrO}_{2}$ membranes is due to the decrease of permeation as expected. The stage cut of double coated membrane is slightly higher than that 
of single coated membrane. It is possibly due to less in-depth fouling because of smaller pores on top layer. Separation and gas permeation results illustrate that the supported $\mathrm{ZrO}_{2}$ membrane is crack and defect free.

\section{Conclusion}

A crack-free ultrafiltration zirconia membrane is successfully synthesized on the top of a disc by sol-gel method using zirconium butoxide. The esterification of acetic acid and alcohol is confirmed and is a feasible means of providing the water necessary for hydrolysis. The water is released homogeneously, resulting in a controllable hydrolysis. Acetic acid also plays an important role in the hydrolysis process through the chelation, thereby stabilizing zirconium alkoxide. Acid peptization can give a stable sol, which makes the spin-coating on the disc reproducible. The results of gas permeation and ultrafiltration indicate that the zirconia membrane is defect-free. This improved sol-gel method is highly promising for use in large-scale manufacturing of membranes in industry.

\section{Nomenclature}

$F / L \quad$ permeance $\left[\mathrm{mole} /\left(\mathrm{m}^{2} \mathrm{Pas}\right)\right]$

$L \quad$ membrane thickness [m]

$r \quad$ pore radius [m]

$M \quad$ gas molecular weight $[\mathrm{g} / \mathrm{mol}]$

$p_{\text {avg }} \quad$ average of feed and permeate pressure [Pa]

$R \quad$ gas constant, $[8.314 \mathrm{j} /(\mathrm{mol} \mathrm{K})]$

$T \quad$ temperature $[\mathrm{K}]$

\section{Greek Symbols}

$\alpha \quad$ intercept, in Eq (6) and (7).

$\beta \quad$ slope, in Eq (6) and (7).

$\mu \quad$ viscosity of gas [poise]

$\tau$ tortuosity

$\varepsilon \quad$ porosity

\section{Acknowledgements}

The authors are grateful for the financial support of National Science Council, Taiwan, Republic of China under the project number NSC-86-2214-E-002-009, and the partial support from the Tzong Jwo-Jang Educational Foundation, contract no. 87-S-029, under the auspices of Tjing-Ling Industrial Research Institute, National Taiwan University.

\section{References}

[1] H.P. Hsieh, Inorganic Membrane Reactors - A Review, in: R. Govind, N. Itoh (Eds.), Membrane Reactor Technology, AIChE symposium series 268, vol. 85, 1989, p. 53.

[2] T. Yazawa, H. Tanaka, H. Nakamichi, T. Yokoyama, Preparation of water and alkali durable porous galss membrane coated on porous alumina tubing by sol-gel method, J. Membr. Sci. 60 (1991) 307.

[3] A.J. Burggraaf, K. Keizer, Synthesis of inorganic membranes, in: R.R. Bhave (Ed.), Inorganic Membranes, Synthesis, Characterization and Applications, Van Nostrand Reinhold, New York ,1991, chap. 2.

[4] L. Cot, Ch. Guizard, A. Larbot, Novel ceramic material for liquid separation process: present and prospective applications in microfiltration and ultrafiltration, Ind. Ceramic 8 (3) (1988) 143.

[5] A. Larbot, J.P. Fabre, C. Guizard, L. Cot, Inorganic membranes obtained by sol-gel technique, J. Membr. Sci. 39 (1988) 203.

[6] A. Julbe, C. Guizard, A. Larbot, A.L. Cot, A. Giroir-Fendler, The sol-gel approach to prepare candidate microporous inorganic membranes for membrane reactors, J. Membr. Sci. 77 (1993) 137.

[7] C.J. Brinker, R. Sehgal, S.L. Hietala, R. Deshpande, D.M. Smith, D. Loy, C.S. Ashley, Sol-gel strategies for controlled porosity inorganic materials, J. Membr. Sci. 94 (1994) 85.

[8] C. Guizard, N. Cygankiewicz, A. Larbot, L. Cot, Sol-gel transition in zirconia systems using physical and chemical processes, J. Non-Crystalline Solids 82 (1986) 86.

[9] M.J. Muñoz-Aguado, M. Gregorkiewitz, A. Larbot, Sol-gel synthesis of the binary oxide $(\mathrm{Zr}, \mathrm{Ti}) \mathrm{O}_{2}$ from the alkoxides and acetic acid in alcoholic medium, Res. Bull. 17 (1992) 87.

[10] S. Doeuff, M. Henry, C. Sanchez, Sol-gel synthesis and characterization of titanium oxo-acetate polymers, Mater. Res. Bull. 25 (12) (1990) 1519.

[11] J. Etienne, A. Larbot, A. Julbe, L. Cot, A microporous zirconia membrane prepared by the sol-gel process from zirconyl oxalate, J. Membr. Sci. 86 (1994) 95.

[12] S. Doeuff, M. Henry, C. Sanchez, J. Livage, Hydrolysis of the titanium alkoxides: modification of the molecular precusor by acetic acid, J. Non-Crystalline Solids 89 (1987) 206.

[13] C. Wolf, C. Rüssel, Sol-gel formation of zirconia: preparation, structure and rheology of sols, J. Mater. Sci. 27 (1992) 3749

[14] J.D. Wang, The Study of Spin Coating, Ph. D. Thesis, National Taiwan University, 1995.

[15] J.C.-S. Wu, E.H. Lee, Ultrafiltration of soybean oil/hexane extract by porous ceramic membrane, J. Membr. Sci. 154 (1999) 251. 
[16] A. Larbot, J.-P. Fabre, C. Guizard, L. Cot, J. Gillot, New inorganic ultrafiltration membranes: titania and zirconia membranes, J. Am. Ceramic Soc. 72 (2) (1989) 257.

[17] Q. Xu, M.A. Anderson, Sol-gel route to synthesis of microporous ceramic membranes: thermal stability of $\mathrm{TiO}_{2}-\mathrm{ZrO}_{2}$ mixed oxides, J. Am. Ceramic Soc. 76 (8) (1993) 2093.

[18] Y.S. Lin, A.J. Burggraaf, Preparation and characterization of high-temperature thermally stable alumina composite membrane, J. Am. Ceramic Soc. 74 (1) (1991) 219.

[19] Y.S. Lin, A.J. Burggraaf, Experimental studies on pore size change of porous ceramic membranes after modification, J. Membr. Sci. 79 (1) (1993) 65.

[20] M. Mulder, Basic Principles of Membrane Technology, Kluwer Academic Publishers, Dordrecht, 1991, p. 204 and 230-231. 